\title{
Olekranon kırıkları ve transolekranon kırıklı çıkıkları
}

\section{Fractures of the olecranon and transolecranon fractured dislocations}

\author{
Serkan Aykut ${ }^{1}$, Yüksel Özkan² \\ ${ }^{1}$ Metin Sabancı Baltalimanı Kemik Hastalıkları Eğitim ve Araştırma Hastanesi, El Cerrahi Kliniği, İstanbul \\ ${ }^{2}$ Şevket Yılmaz Eğitim ve Araştırma Hastanesi, Ortopedi ve Travmatoloji Kliniği, Bursa
}

\begin{abstract}
Olekranon kırıkları günlük ortopedik travma pratiğinde oldukça sık görülürler. Dirsek çevresi kırıkların yaklaşık \%10'unu oluşturan olekranon kırıkları basit transvers kırıklardan kompleks kırıklı çıkıklara uzanan geniş bir çeşitlilikte görülebilirler. Tümü eklem içi kırıklar olduğundan, tedavileri büyük çoğunlukla cerrahidir. Seçenekler; gergi bandı yöntemi, plak ile tespit, kanal içi tespit ve kırık parçanın çıkartılarak trisepsin ilerletilmesi olarak sayılabilir. Olekranon kırıkları uygun bir tespit ve erken hareket ile sorunsuz olarak iyileşebilir. Ancak yaralanma mekanizması, kırı̆̆ın tipi ve anatominin iyi bilinmesi potansiyel artsorunlardan kaçınmada önemli rol oynar. Uygun eklem onarımı sağlanmadığında sert dirsek ve eklem yangısı kaçınılmaz problemlerdendir.
\end{abstract}

Anahtar sözcükler: kemik kırıkları; olekranon; dirsek eklemi; proksimal, ulna
Olecranon fractures are the most frequently seen fractures in daily orthopaedic traumatology practice. They consist approximately $10 \%$ of fractures around elbow and range from simple transvers fractures to complex fractured dislocations. Because all these fractures are intra-articular, majority are treated surgically. Surgical options are, tension-band wiring, plate fixation, intramedullary fixation, and triceps advancement after fragment excision. The treatment of olecranon fractures with an appropriate fixation and early mobilization create no problems. But it must be kept in mind that knowing the injury mechanism, the type of fracture and also well-known anatomy play an important role in preventing complications. Stiff elbow or arthritis is unavoidable unless a proper repair of the joint ensured.

Key words: bone fractures; olecranon; elbow joint; proximal, ulna

da kanal içi vida tespiti ve kırık parçanın çıkartılarak trisepsin ilerletilmesi gibi birçok seçenek sayılabilir.

Kırıklar genellikle eklem içi şeklinde görüldüğünden, tedavinin amacı anatomik bir eklem yüzeyi elde ederek erken harekete izin veren dengeli bir tespit yapmaktır.

\section{ANATOMI}

Olekranon, koronoid çıkıntı proksimali ile birlikte troklea ile eklemleşen sigmoid çentiği oluşturur. Kompleks dirsek ekleminde olekranonun birincil görevi ulnanın humerusa göre öne yer değiştirmesine engel olmaktır. Olekranonun kemikleşme merkezi 9-10 yaşlarında görülürken, 14 yaş civarında proksimal ulna ile kaynaşması gerçekleşir. ${ }^{[1]}$ Fizisin kalıcı hale gelmesi erişkin çağda görülebilen bir durumdur; genellikle de ailesel ve bilateraldir. Ayrıca, "patella cubiti" olarak isimlendirilen trisepsin

- İletişim adresi: Doç. Dr. Yüksel Özkan, Şevket Yılmaz Eğitim ve Araştırma Hastanesi Ortopedi ve Travmatoloji Kliniği, Yıldırım, Bursa Tel: 0224 - 2955000 e-posta: dryukselozkan@yahoo.com

- Geliștarihi: 10 Ocak2014 Kabul tarihi: 10 Ocak 2014 
distal aksesuvar kemikleşme merkezi de kırıklar ile karıştırılmaması gereken bir durumdur. ${ }^{[1]}$

Olekranon ve koronoid çıkıntının eklem yüzleri hiyalin kıkırdak ile kaplıdır. Olekranon ve koronoid çıkıntının uç kısımlarının orta noktasının geçtiği hat "bare bölge" olarak isimlendirilir ve kıkırdaktan yoksun bir alandır. ${ }^{[4-5]}$ Cerrahi sırasında eklemin yerine oturtulmasında aşırı kompresyon sonucu bu bölümün ortadan kaldıılarak kıkırdak kısımların karşııklı getirilmesi teknik bir hatadır ve olekranon fossayı daraltarak uyumsuz bir yerine oturtmaya yol açar. ${ }^{[6]}$ Olekranon osteotomisi gerektiren durumlarda da bu işlem "bare bölge"den yapılmalıdır. ${ }^{[4-5]}$

Triseps tendonu olekranon posteriorunun 1/3'lük kısmına yapışır, olekranonun periostu triseps tendonu ile birleşirken, brakiyalis kası da geniş bir yelpaze şeklinde koronoid çıkıntı önü ve proksimal ulna metafizine yapışır. Ulnar sinir, dirsek ekleminin iç yan yüzü boyunca uzanarak öne döner ve ulnar arter ile birlikte nörovasküler demeti oluşturur. Bu demet, gergi bandı yöntemi uygulanırken K-tellerinin ucu ön korteksi geçtiğinde, yaralanma riski altındadır. ${ }^{[7]}$

\section{YARALANMA MEKANIZMASI}

Olekranonun cilt altı yerleşimi bu bölge kırıklarını direkt travmaya yatkın hale getirir. Kırıklar direkt trav$\mathrm{ma}$, indirekt travma ya da her ikisinin bileşimi şeklinde görülebilir. Kırıkların çoğunluğu alçak mesafeden düşme ile olekranon üzerine direkt darbe ya da güçlü ekstansiyon yapıldığında görülür. ${ }^{[1]}$ Açık el üzerine düşme sırasında triseps kasının güçlü kasılması neticesinde, genellikle transvers ya da kısa oblik kırık ile sonuçlanabilir. En sık yaralanma nedenleri arasında da araç içi trafik kazaları, motosiklet kazaları ve saldırılar yer almaktadır. Açık kırıklar değişik kaynaklarda \%2-31 olarak bildirilmektedir. ${ }^{[6,8]}$

\section{SINIFLANDIRMA}

Sayısız sınıflandırma sistemi tanımlanmıştır ama evrensel olarak kabul edilen bir sınıflandırma yoktur. ${ }^{[6]}$ Klinik uygulamada en sık kullanılan sistemlerden biri Mayo sınıflamasıdır (Şekil 1). Bu sınıflamada parçalanma durumuna göre alt gruplar oluşturularak başlıca üç gruba ayrılır: Tip I, ayrılmamış kırıklardır; Tip II, ayrılmış kırıklardır ve olekranon kırıklarının en sık (\%85) görülen

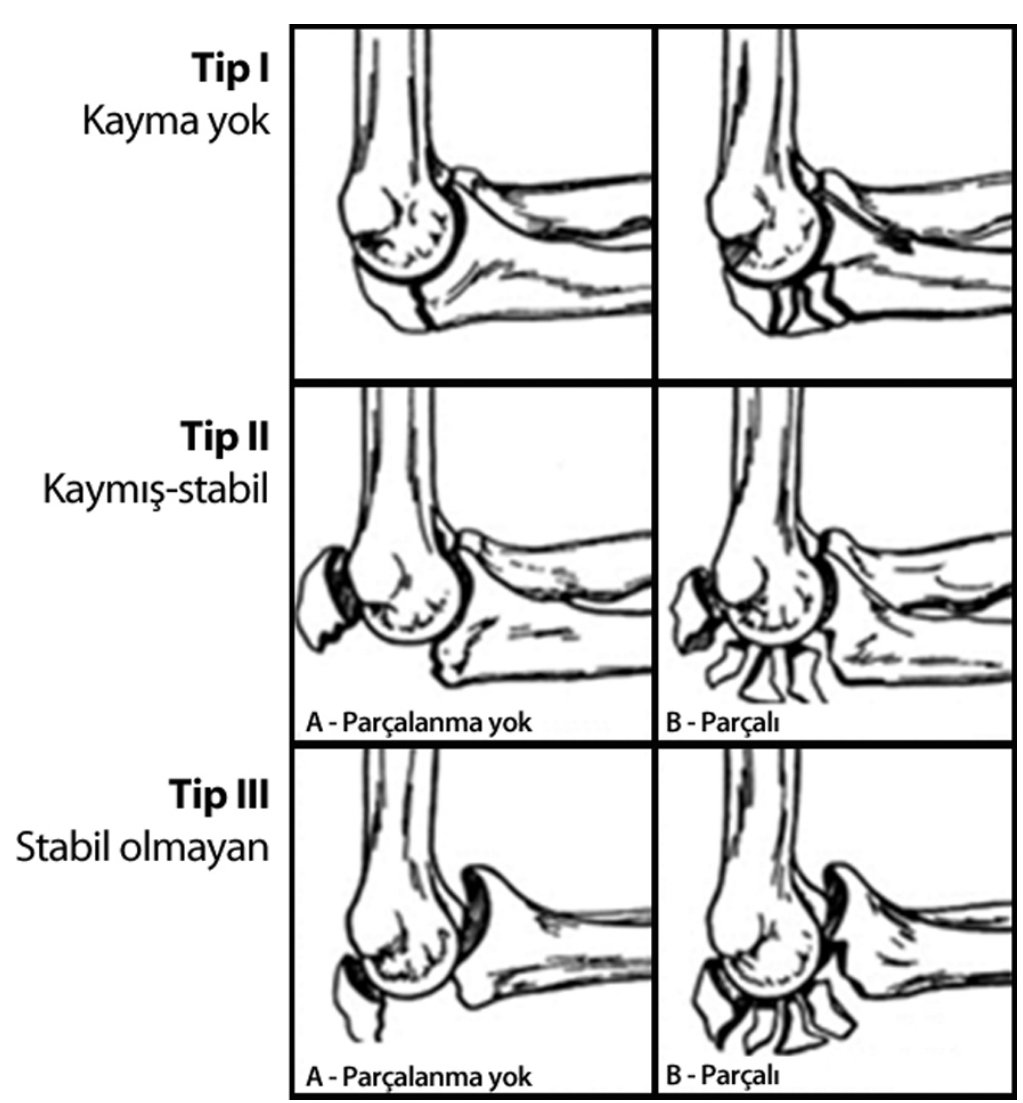

Şekil 1. Olekranon kırıklarında Mayo sınıflandırması (The American Society for Surgery of the Hand, Copyright ${ }^{\mathcal{O}} 2013$ Elsevier'in izniyle basılmıştır). ${ }^{[19]}$ 
tipidir; ${ }^{[1]}$ Tip III ise dengesiz kırıklardır ve ek yaralanmalar eşlik eder. Her grup, parçalanma varlığına göre de $A$ ve $B$ şeklinde alt gruplara ayrilır. AO (Association for Osteosynthesis) sınıflandırması da kullanılabilecek bir sistemdir, ancak daha çok araştırma ve akademik çalışmalarda tercih edilen bir sınıflandırmadır. AO sınıflandırmasında proksimal radius ve ulnanın kırıkları üç ana kategoriye ayrilır. Tip A, radius ve/veya ulna proksimalinin eklem dışı metafızer kırığıdır; Tip B, kırıklar radius ve/veya ulnanın eklem içi kırıklarıdır, B1 alt tipi sadece olekranonun eklem içi kırı̆ııdır; Tip C kırıklar ise radius başı ve olekranonun eklem içi kırıklarıdır (Şekil 2).

Schatzker'in sınıflandırması, uygulanacak iç tespitin belirlenebileceği mekanik değerlendirmeleri içerir. Altı tipi vardır: Tip A, basit transvers kırık; Tip B, santral kısımda çökme ile birlikte kompleks transvers kırık; Tip C, basit oblik kırık; Tip D, parçalı kırık; Tip E, troklear çıkıntı distalinde oblik kırık; Tip F ise radius başı kırığının ve sıklıkla mediyal kollateral bağın yaralanmasının eşlik ettiği kompleks kırıklardır (Şekil 3).

Kırıkların tedavisinde en önemli nokta ayrılma ve parçalanmadır. Eşlik eden pek çok yaralanma bulunabilir; bunlar tek tek belirlenmeli ve patolojiye özel tedaviler planlanmalıdır.

\section{TANISAL DEĞERLENDIRME}

Olekranon kırıklarının çoğu yalın yaralanmalardır. Ek bir yaralanma eşlik ettiğinde ise bu genellikle aynı uzvu tutar. Üst uzvun, omuzdan, klavikuladan başlayarak ele kadar dikkatli bir muayene ve değerlendirilmesi temeldir. Dirsek genellikle şiştir ve eklemde sıvı birikimi bulunur. Olekranon kırığının cilt altı yerleşimi onu elle muayeneye elverişli kılar ve bu sayede kırık hattında kemikteki devamsızlık ve çökme kolaylıkla fark edilebilir. Açık kırıklar açısından cilt dikkatlice incelenmelidir. Damar ve sinir muayenesi ayrıntılı olarak yapılmalı ve hasta dosyasına mutlaka kaydedilmelidir.

Yalın kırıklarda standart ön-arka ve yan dirsek radyografileri genellikle yeterlidir. Kırı̆ıın tam ve doğru tespiti ile eşlik eden koronoid, humerus distal, radius başı kırıkları veya çıkıkların belirlenebilmesi için yan grafi mutlaka tam yan durumda çekilmelidir. Radyokapitellar oblik görüntüleme, radius başı ve/veya kapitellar makaslama kırığının tespitinde yararlıdır.

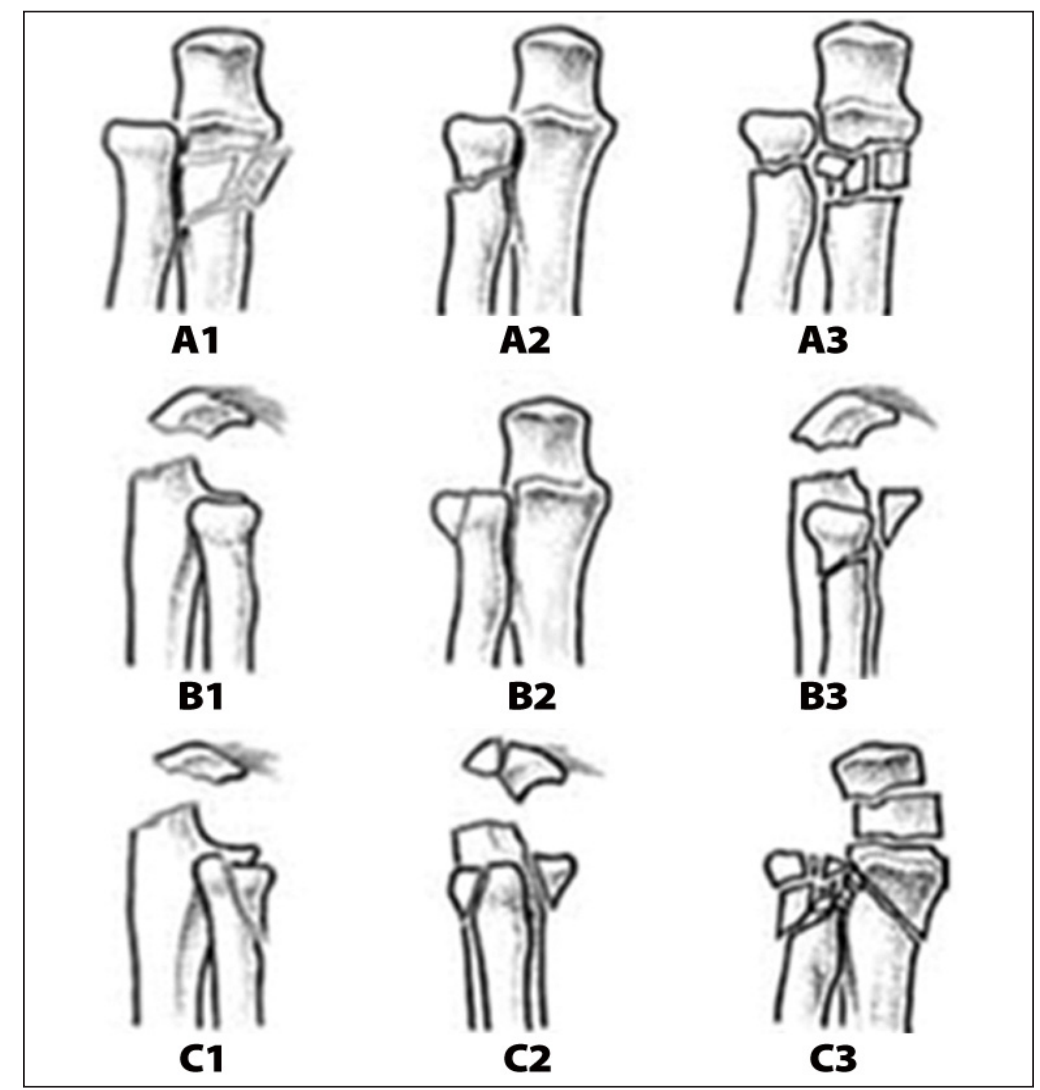

Şekil 2. Olekranon kırıklarında AO sınıflandırması. ${ }^{[19]}$ (The American Society for Surgery of the Hand, Copyright ${ }^{\odot} 2013$ Elsevier'in izniyle basılmıştır.) 


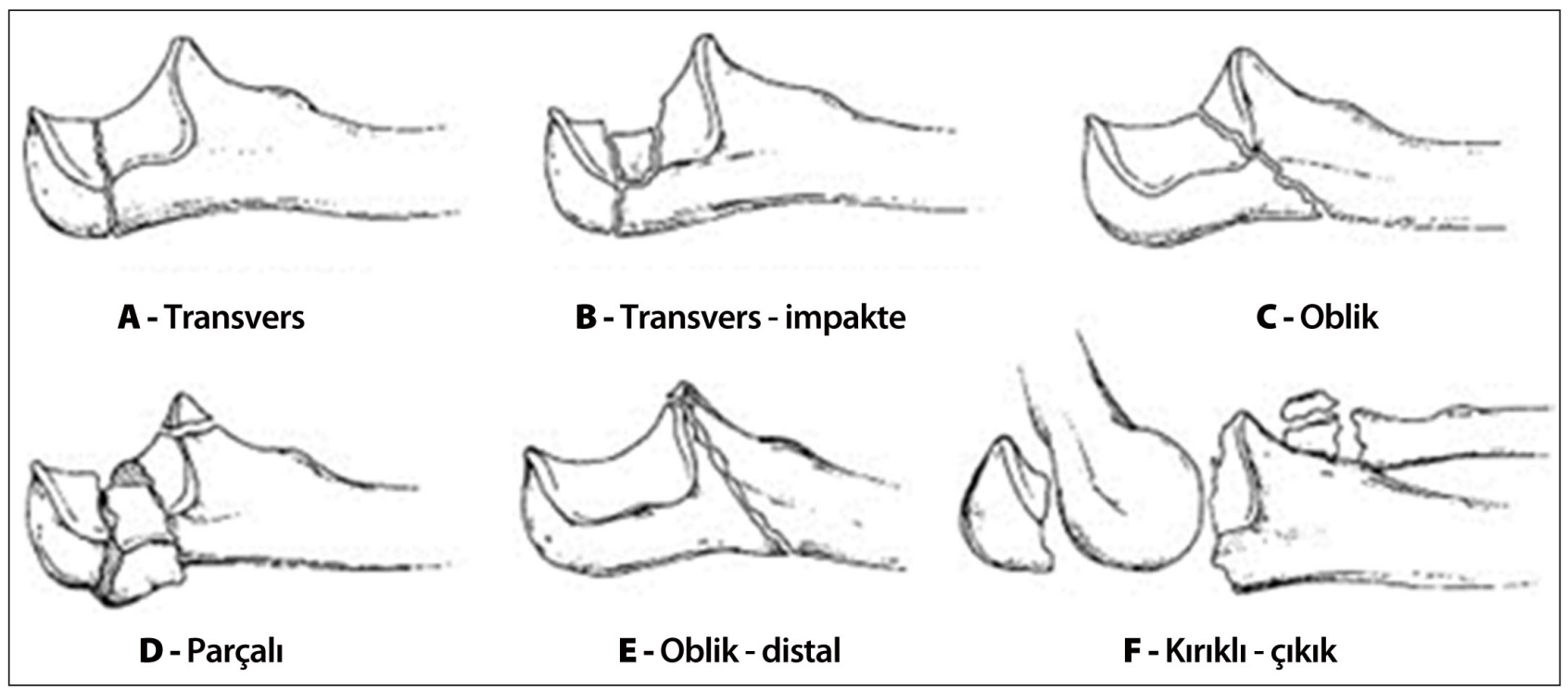

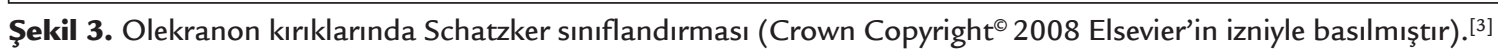

\section{TEDAVi}

Olekranon kırıklarının tümü eklem içi kırıklardır. Bundan dolayı tedavinin amacı, AO grubunun tanımladığı gibi, eklem yüzeyinin anatomik onarımı, kırığın kesin ve mutlak tespiti ve erken hareketin sağlanabilmesidir. Tedavi seçeneğinin belirlenmesinde öncelikle kırığın tipi ve yapılanması, hastanın ek hastalıkları ve fonksiyonel beklentileri değerlendirilmelidir. Tedavinin planlanmasında Mayo sınıflandırmasından yararlanılabilir (Tablo 1).

Olekranonun kaymamış kırıkları için (Mayo Tip IA ve IB) konservatif tedavi planlanabilir. Bu kırıklar kaymanın 2 mm'nin altında olduğu, dirseğin nazikçe $90^{\circ}$ ye kadar getirilmesi ile ya da yer çekimi gücüne karşı dirseğin tam ektansiyona getirilmesi ile kırığın pozisyonunda değişikliğin olmadığı olgulardır. Konservatif tedavide dirsek $45-90^{\circ}$ fleksiyon aralığında 3-4 hafta kadar tespit edilir. ${ }^{[6]}$ Takibinde dirseğe $90^{\circ}$ 'ye kadar fleksiyon hareketi verilmeye başlanır. Ortalama 6-8. haftada radyografik kaynama bulgularının görülmesi ile hareket arttırılır. Daha yaşlı hastalarda sert dirsek gelişebileceğinden, tespit süresi üç haftanın altında tutulmalıdır. ${ }^{[9]}$ Hastaların ilk kontrolleri 5-7. günde yapılarak, kırıkta kaymanın olup olmadığı değerlendirilmelidir. Sert dirsek gelişme riski daha çok olduğundan,

Tablo 1. Mayo sınıflamasına göre tedavi planlanması ${ }^{[3]}$

\begin{tabular}{|c|c|c|}
\hline Sınıflandırma & Tanımlama & Tedavi \\
\hline Mayo Tip IA ve IB & $\begin{array}{l}\text { Kaymamış kırıklar (<2 mm), } \\
\text { parçalanma yok (IA) ya da var (IB) }\end{array}$ & Atel ile tespit, erken hareket, yakın takip \\
\hline Mayo Tip IIA & $\begin{array}{l}\text { Dengeli kırıklar (>3mm fazla } \\
\text { kayma), parçalanma yok }\end{array}$ & $\begin{array}{l}\text { Genellikle gergi band tekniği için uygundur; kırık hattı koronoid çıkıntı } \\
\text { distalinde ise plak tespiti planlanır, fonksiyonel beklenti az ise ya da kırık parça } \\
\text { küçük ise kırık parça çıkartılabilir }\end{array}$ \\
\hline Mayo Tip IIB & $\begin{array}{l}\text { Dengeli kırıklar (>3mm fazla } \\
\text { kayma), parçalanma var }\end{array}$ & $\begin{array}{l}\text { Plak ve vida tespiti yapılır (özellikle > } 60 \text { yaş); düşük fonksiyonel beklentili } \\
\text { hastalarda, <60 yaş durumunda, ileri derece parçalanma durumunda ya da } \\
\text { parça küçük ise çıartılabilir }\end{array}$ \\
\hline Mayo Tip IIIA & $\begin{array}{l}\text { Dengeli olmayan, kırıklı çıkıklar, } \\
\text { parçalanma yok }\end{array}$ & Plak ve vida tespiti \\
\hline Mayo Tip IIIB & $\begin{array}{l}\text { Dengeli olmayan, kırıklı çıkıklar, } \\
\text { parçalanma var }\end{array}$ & Plak ve vida tespiti \\
\hline Kopma kırıkları & & Gergi band tekniği ya da parçanın çıkartılması \\
\hline
\end{tabular}


tam ekstansiyonda atelleme önerilmez. Bu tip olgular cerrahi olarak tedavi edilmelidir.

Kaymanın görüldüğü olekranon kırıkları cerrahi olarak tedavi edilirler. Cerrahi tedavide başlıca dört yöntem uygulanır:

- Gergi bandı yöntemi (Weber yöntemi).

- Kanal içi tespit.

- Plak ile tespit.

- Proksimal kırık parçanın çıkartılıp trisepsin ilerletilmesi ve yeniden oluşturulması.

Semilunar çıkıntının orta noktasının proksimalinde kalan kırıklar dengeli kabul edilir. Gergi bandı yöntemi, bu tipteki basit transvers kırıklar için etkili bir tespit yöntemidir (Şekil 4). Bu yöntemde trisepsin ekstansör gücünün, eklem yüzeyi boyunca uzanan dinamik kompresif güçlere çevrildiği düşünülmektedir. Ancak bu durum klinik ya da laboratuvar araştırmalarıyla kanıtlanmamıştır. ${ }^{[10]}$

Geleneksel tespit aracı olarak K-telleri kullanılır. Arka giriş yolu ile olekranonun ve kırık hattının ortaya konmasını takiben kırık oturtulur. Olekranonun uç kısmından ön kortekse doğru iki adet 1,6-2 mm'lik K-teli gönderilir. Teller kanal içi olarak da gönderilebilir, ancak bu şekilde gönderildiğinde tellerin proksimale migre olma olasılığı ortaya çıkar. ${ }^{[11,12]}$ Damar sinir demetini yaralamamak için, K-tellerinin anterior kortekste çıktığı nokta koronoid uç noktasının en fazla $15 \mathrm{~mm}$ distalini (ideali $10 \mathrm{~mm}$ ) geçmemelidir. ${ }^{[7]}$ Ayrıca ön korteksi geçen yerleşim, radius boynunun supinatöre ve biseps tendonlarının sıkışması sonucu, ön kolun dönme hareketlerinde kısıtlılığa yol açabilir.. ${ }^{[7]}$ Teller yaklaşık 1 $\mathrm{cm}$ geri çekilerek, kırık hattının 3-4 cm distalinden 2 $\mathrm{mm}$ matkap ucu ile transvers delik açılır. Genel kural olarak açılan deliğin kırık hattına uzaklığı, en az kırık hattı - olekranon ucu arası uzaklık kadar olmalıdır. ${ }^{[13]}$ Yaklaşık 1,5 mm (ya da, 18 gauge $=1,219 \mathrm{~mm}$ ) kalınlığında serklaj teli delikten geçirilerek 8 şekli verilir. Telin proksimal kısmı triseps liflerinin ve K-tellerinin proksimal uçlarının altından geçirilir. Telin çaprazlaşan uçları bir pense yardımı ile birbiri üzerine kıvrılarak ilmek haline getirilir ve yeterli gerginlik sağlanana kadar kıvırma işlemine devam edilir. Illmeğin 3-4 mm'lik kısmı bırakılarak distal kısmı kesilir ve bükülür. K-telleri de bükülür ve ilerletilir. Tespitin tamamlanmasını takiben dirseğin eklem hareket açıklı̆̆ı ile ön kolun rotasyonel hareketleri kontrol edilmeli ve tespitin kararlılığı değerlendirilmelidir. Ameliyathanede radyografik değerlendirme mutlaka yapılmalıdır. K-telleri yerine bir adet 7,3 mm
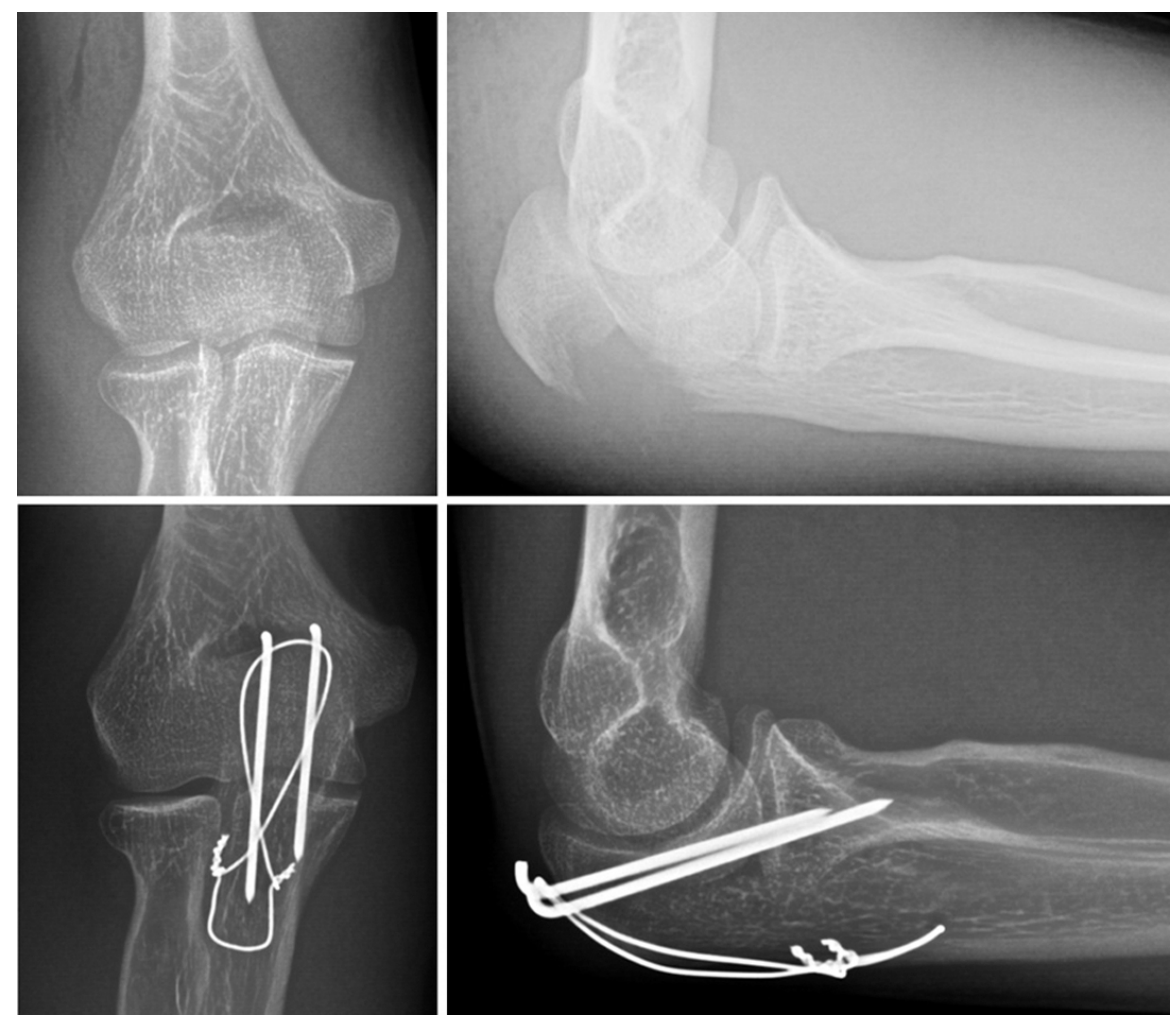

Şekil 4. Yirmi beş yaşında erkek hastada Mayo Tip IIA olekranon kırı̆̆ı. Ameliyat öncesi ve gergi band tekniği ile tespiti sonrası dirsek iki yönlü radyografileri görülmektedir. 
kanal içi vidanın, (gergi bandı tekniği ile kombine ya da tek başına vida gönderilerek) K-teli ile yapılan gergi bandı tekniğine göre eklem yüzeyinde daha iyi kompresyon sağladığını ve kırık hattında aralık oluşmasına direncin daha az olduğunu gösteren çalışmalar olsa $\mathrm{da}$, bunu destekleyen klinik bulgu yoktur. ${ }^{[10,14]}$

Ulusal yayınlarımıza baktığımızda, Burak ve arkadaşları, 41 yer değiştirmiş olekranon kırıklı hastada gergi bandı yöntemi ile 13 olguda çok iyi, 17 olguda iyi, 9 olguda orta, 2 olguda da kötü sonuç elde etmişler,[15] deplase olekranon kırıklı olgularda yöntemin başarılı bir şekilde uygulanabileceğini bildirmişlerdir. Özkaya ve arkadaşları ise, 28 olgunun 21'inde mükemmel ve iyi, 6 hastada orta ve bir hastada kötü sonuç elde etmişler, dengeli kırıklarda uygun teknik ile yapılır ise etkili bir yöntem olduğunu bildirmişlerdir. ${ }^{[16]}$ Çetinus ve arkadaşları ise, cerrahi olarak tedavi ettikleri 9 olgunun 2'sinde çok iyi, 3'ünde iyi, 2'sinde orta sonuç aldıklarını bildirmişlerdir.[17] Weber gergi bandı tekniğini kullanan bir diğer çalışmada ise Önçağ ve arkadaşları, 16 hastadan 11'inde çok iyi, 3'ünde iyi, 2'sinde ise orta sonuç almışlardır. ${ }^{[18]}$

Parçalı transvers kırıklarda (Mayo Tip IIB) gergi bandı yöntemi, kırık parçalarının birbiri üzerinde çökmesine yol açarak eklemi daraltacağından, uygun bir seçenek değildir. Bu kırıklar için en uygun seçenek anatomik az temaslı - dinamik kompresyon plağı (Limited Contact - Dynamic Compression Plate - LC-DCP) tespiti ile parçalanmanın derecesi ve kemik kaybına bağlı olarak kemik greftlemesidir. Benzer olarak, oblik kırıklarda ve kaymış olekranon kırıklı çıkıklarında (Mayo Tip IIIA ve IIIB) gergi bant yöntemi yetersiz kalacağından plak ile tespit seçeneği öne çıkmaktadır (Şekil 5). Plak seçenekleri ise: $1 / 3$ tübüler plak, $3,5 \mathrm{~mm}$ önceden şekil verilmiş LC-DCP, 3,5 mm kanca plak ve önceden şekil verilmiş kilitli plaklardır. Önceden şekil verilmiş kilitli vida gönderme seçeneği olan plaklar, deneyimin artması ile günümüzde daha yaygın kullanılır hale gelmiştir.

Önceden şekil verilen plakların hemen hiçbiri ulnanın kemik yapısı değerlendirilmeden uygulanmamalı, ulna morfolojisinde varyasyonlar olabileceği unutulmamalıdır. Özellikle, kullanılacak plak proksimal ulnar dorsal açılanmaya uygun olmalıdır (ortalama $\left.5,7^{\circ}, 0-14^{\circ}\right) . .^{19]}$ Ulnaya düz plak uygulanması durumunda, plak kırık hattını kötü kaynama pozisyonuna zorlayacaktır. ${ }^{[20]}$ Çok parçalı kırıklarda 1/3 tübüler plak kullanımı yeterli gerginliği sağlayamadığından materyal yetmezliğine yol açabilir. ${ }^{[6]}$

Parçalı kırıklarda, kırık paterni tipik olarak üçgen benzeri bir koronoid parçası içerir; kırığın dengesi
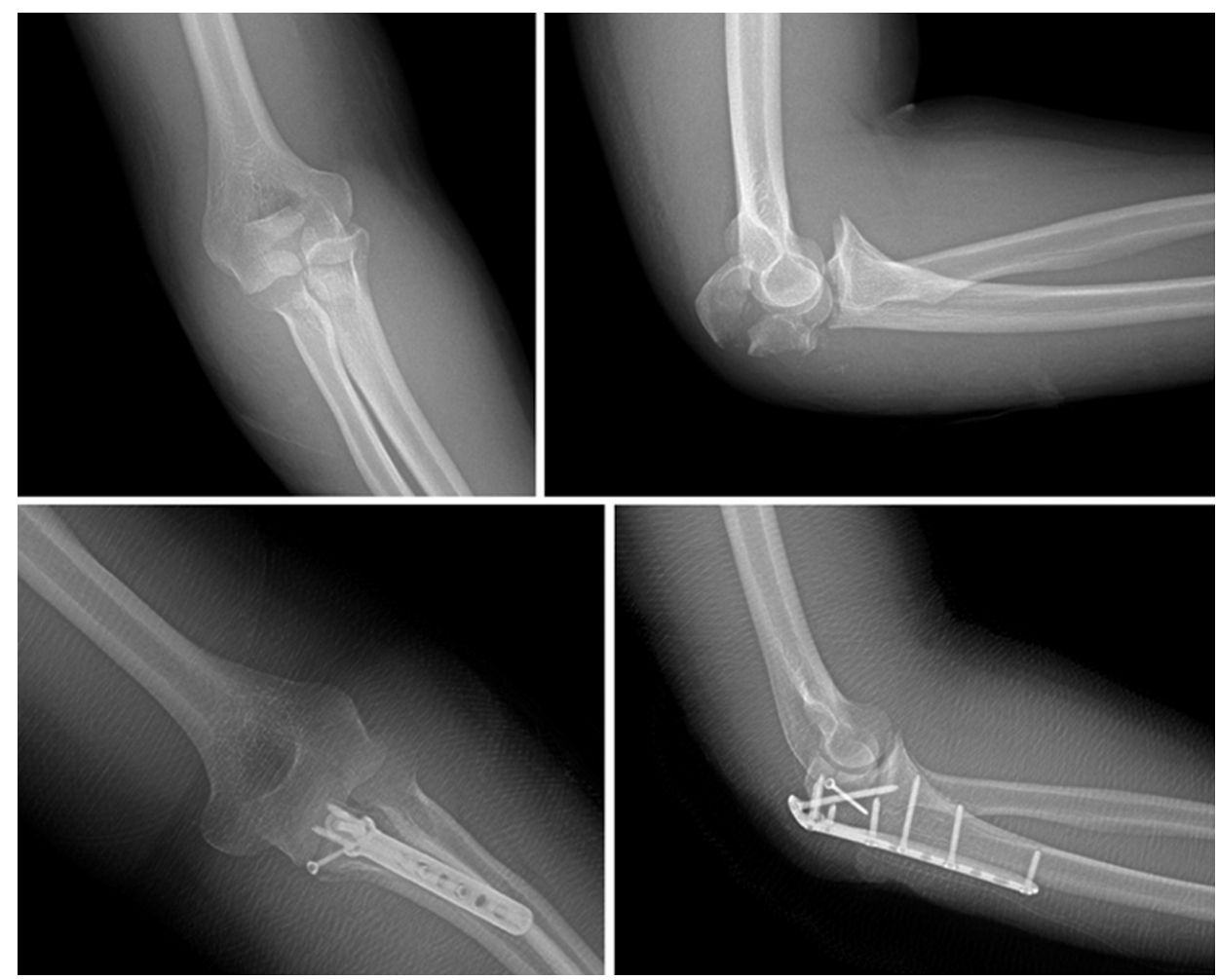

Şekil 5. Otuz yaşında erkek hastada Mayo Tip IIB olekranon kırığı. Ameliyat öncesi ve parçalar arası vida ve plak ile tespiti sonrası dirsek iki yönlü radyografileri görülmektedir. 
için, bu parçanın öncelikli tespiti önemlidir. ${ }^{[13]}$ Bu parça, öncelikle parçalar arası vida ile tespit edilmelidir. Plaklar en çok ulnanın dorsal yüzeyine uygulanır; bu yüz ulnanın biyomekanik olarak sağlam tarafıdır; koronoide doğru ya da kanal içine gönderilen vidalar ile tespit güçlendirilebilir. Çökmüş eklem parçaları varlığında, kemik grefti uygulaması gereklidir. Ayrıca, plağın proksimal kısmı olekranonun uç kısmı üzerine oturduğundan, kemik kalitesi kötü olanlarda proksimal parçanın oturtulmuş kalmasına destek olur. ${ }^{[9]}$ Ertürer ve arkadaşları, 18 parçalı olekranon kırıklı hastalarına LC-DCP anatomik olekranon plağı uyguladıkları çalışmalarında, Morrey skalasına göre 4 olguda çok iyi, 8 olguda iyi, 5 olguda orta ve bir olgularında kötü sonuç elde etmişlerdir. ${ }^{[21]}$ Cilt altı yerleşimi plağın çıkıntı yaparak rahatsızlık verebileceği gibi endişelere yol açsa da, semptomatik materyal rahatsızlığı gergi bandı tekniğindekine göre daha düşüktürr. ${ }^{[22,23]}$

Olekranonun dengeli olmayan kırıklarının daha katı tespit gerektiriyor olması plak tespitini ön plana çıkartsa da, kanal içi tespit yöntemlerinin de çeşitli avantajları olduğu ileri sürülmektedir. ${ }^{[24,25]}$ Çivinin, medulla içi yerleşimiyle geleneksel plaklara göre daha etkin bir yük aktarımı sağladığı, daha kısa olan kaldıraç kolunun beklenen implant gerilimini azalttığı ve yumuşak dokuların daha az zarar görmesi neticesi periosteal damarlanmayı koruyacağı; sonuçta, teorik olarak kırık kaynamasının fazla olacağı, enfeksiyon oranının az olacağı ve daha hızlı iyileşme olacağı düşünülmektedir. ${ }^{[24,25]}$ Kadavra modelinde, kilitli plak ile çivilemenin karşılaştıııldığı çalışmada, her iki implantın da parçaları eşit ölçüde kontrol altına aldığı, çivilerin plaklara göre anlamlı ölçüde kuvvet yüklendiği gösterilmiştir. ${ }^{[25]}$

Proksimal kırık parçanın çıkarılması ve trisepsin ilerletilmesi, ilk adımda tercih edilen bir tedavi değildir. Genellikle proksimal parçanın çok küçük ve/veya parçalanmış olduğu, osteoporotik, internal tespitin başarısız olduğu ya da mevcut riskler nedeniyle başarısız olacağına kanaat getirilen olgularda kurtarıcı girişim olarak düşünülmelidir. ${ }^{[9,19]}$ Bu tekniğin gerekliliği, koronoidin, anterior yumuşak dokuların, kollateral bağların ve interosseöz membranın sağlam olmasıdır; aksi halde, dengesizlik ile sonuçlanır. ${ }^{[9]}$ Triseps tendonu eklem yüzeyine bitişik kısıma kemikten geçirilen tüneller aracılığıyla dikilir. Trisepsin bu şekilde dikilmesi troklea için askı sistemi yaratır ve düzgün bir yüzey oluşturur; ancak, moment kolu kısaldığından ekstansör mekanizmada zayıflıkla sonuçlanır. ${ }^{[9]}$

\section{REHABILITASYON}

Dirsek cerrahisinde, ameliyat sonrası sertlik gelişimini engellemede erken hareketin rolü çok önemlidir.
Olekranon kırıklarının çoğunda cerrahi tedavi sayesinde yeterli bir tespit sağlanabildiğinden, eklem hareket açıklığı egzersizlerine erken dönemde başlanabilir. Illeriye dönük çalışmalarda harekete başlanılabilecek ideal zaman gösterilmese de, cerrah tespitin yeterliliğini, kırığın dengesini, hastanın uyumunu ve yara iyileşmesi gibi kriterleri göz önünde bulundurarak karar vermelidir. ${ }^{[6]}$ Aktif hareket ve germe egzersizleri için radyografik kaynama beklenmelidir; bu genellikle 6-8. haftayı bulabilir. ${ }^{[9,19]}$ Daha kompleks ve parçalanmalı kırıklarda ise daha uzun tespit gerekli olabildiğinden, sert dirsek kaçınılmaz olabilir ${ }^{6}$. Denge için endişe duyulan olgularda, menteşeli breys ilave bir destek sağlayabilir. ${ }^{[9]}$

\section{ARTSORUNLAR}

Olekranon kırıklarını takiben uç, yani son ekstansiyonda kayıp sıklıkla beklenen bir artsorun olduğundan hastalar ameliyat öncesi mutlaka bu konuda bilgilendirilmelidir. ${ }^{[19]}$ İzole yaralanmalı olgularda tipik olarak 10-15 ekstansiyon kaybı olabilir. ${ }^{[26]}$ Parçalanmalı kırıklar ya da açık kırıklar hareket kaybına daha yatkındır. ${ }^{[6]}$

En yaygın görülen artsorun ise materyale bağlı rahatsızlık ve ağrıdır; yayınlarda \%3-80 aralığında sıklık bildirilmiştir. ${ }^{[20,22,27,28]}$ Tel migrasyonu, yumuşak doku rahatsızlığı, olekranon bursiti, tel kırılması, kırık deplasmanı gergi bandı yönteminde görülebilen diğer artsorunlardır. ${ }^{[29]}$ Simpson ve arkadaşları, LC-DCP uygulaması sonrası semptomatik materyal rahatsızlığı görmediklerini bildirseler de Bailey ve arkadaşları, olgularının \%20'sinde plağın çıkartılmasını gerektirecek kadar rahatsızlık görmüşlerdir. ${ }^{[20]}$

Olekranon kırıkları sonrası \%1'in altında bir oranda kaynama yokluğu görülür; hastalar genellikle ağrı, dirsekte dengesizlik ya da hareket kaybı ile başvururlar. Tedavi seçenekleri, kırık parçanın çıkartılması, LC-DCP ile osteosentez ve kemik grefti ya da artroplastidir. ${ }^{[30]}$

Dirsek eklemi, diğer eklemlerle karşılaştırıldığında yumuşak dokudan oldukça yoksundur. Bu nedenle enfeksiyon riski ve yara problemleri ciddiye alınması gereken artsorunlardır. [ ${ }^{19]}$ Ameliyat sonrası yara yeri eritematöz bir hale gelir ya da yarada açılma olursa, agresif yaklaşımlar uygulanmalıdır.[ 19] Böyle bir durumda, hastanın oral antibiyotikler ile taburculuğu veya takibi kabul edilemez bir durumdur. Yumuşak doku az olduğundan, her hangi bir yüzeyel enfeksiyon kolaylıkla derin dokulara yayılım gösterebilir. ${ }^{[19]}$

\section{ÇIKARIMLAR VE SONUÇ}

Sonuç olarak, olekranon kırıkları günlük ortopedik travma pratiğinde sık görülen, genellikle tedavi 
algoritmasına uyulduğunda ve doğru teknik uygulandığında tatmin edici sonuçlar alınabilen kırıklardır. Ancak, bu kırıkların kompleks dirsek yaralanmalarının bir parçası olabileceği unutulmamalıdır. Hareket kısıtılığı ve materyale bağlı rahatsızlık gibi sık görülen artsorunlar konusunda hastalar mutlaka bilgilendirilmelidir.

\section{KAYNAKLAR}

1. AdamsJE, Steinmann SP. Fracture of the olecranon. In: Morrey BF, Sanchez-Sotelo J, editor. The Elbow and Its Disorders. 4th edition. Philedelphia: Saunders, Elsevier; 2009. p.389-400.

2. Rommens PM, Küchle R, Schneider RU, Reuter M. Olecranon fractures in adults: factors influencing outcome. Injury 2004;35(11):1149-57.

3. Newman SDS, Mauffrey C, Krikler S. Olecranon fractures. Injury 2009;40(6):575-81. CrossRef

4. Wang AA, Mara M, Hutchinson DT. The proximal ulna: an anatomic study with relevance to olecranon osteotomy and fracture fixation. J Shoulder Elbow Surg 2003;12(3):293-6.

5. Akman Ş, Seyahi A. Olekranon ve koronoid çıkıntı kırıkları. İçinde: Kesmezacar H, editör. Omuz ve Dirsek Bölgesi Kırık ve Çıkıkları. İstanbul: Bayçınar Tıbbi Yayıncılık ve Reklam Hizmetleri; 2010. p.125-40.

6. Hak DJ, Golladay GJ. Olecranon fractures: treatment options. J Am Acad Orthop Surg 2000;8(4):266-75.

7. Catalano LW, Crivello K, Lafer MP, Chia B, Barron OA, Glickel SZ. Potential dangers of tension band wiring of olecranon fractures: an anatomic study. J Hand Surg Am 2011;36(10):1659-62. CrossRef

8. Duckworth AD, Clement ND, Aitken SA, Court-Brown CM, McQueen MM. The epidemiology of fractures of the proximal ulna. Injury 2012;43(3):343-6. CrossRef

9. Veillette CJ, Steinmann SP. Olecranon fractures. Orthop Clin North Am 2008;39(2):229-36. CrossRef

10. Hutchinson DT, Horwitz DS, Ha G, Thomas CW, Bachus $\mathrm{KN}$. Cyclic loading of olecranon fracture fixation constructs. J Bone Joint Surg Am 2003;85-A(5):831-7.

11. Huang TW, Wu CC, Fan KF, Tseng IC, Lee PC, Chou YC. Tension band wiring for olecranon fractures: relative stability of Kirschner wires in various configurations. J Trauma 2010;68(1):173-6. CrossRef

12. van der Linden SC, van Kampen A, Jaarsma RL. K-wire position in tension-band technique affects stability of wires and longterm outcome in surgical treatment of olecranon fractures. J Shoulder Elbow Surg 2011;21(3):405-11. CrossRef

13. McKee MD, Jupiter JB. Trauma to the adult elbow and fractures of the distal humerus. In: Browner BD, Levine AM, Jupiter JB, Trafton PG, Krettek C, editors. Skeletal Trauma: Basic Science, Management, and Reconstruction, 4th ed. Philadelphia: WB Saunders; 2009. p.1459-502.
14. Murphy DF, Greene WB, Gilbert JA, Dameron TB Jr. Displaced olecranon fractures in adults. Biomechanical analysis of fixation methods. Clin Orthop Relat Res 1987;(224):210-4.

15. Burak C, Orhan Z, Demirkaya M, Yazıcı N. Deplase olekranon kırıklarının Zuggurtung tekniği ile osteosentezi. Ulus Travma Dergisi 2000;6(3):180-4.

16. Özkaya U, Kabukçuoğlu Y, Parmaksızoğlu AS, Gül M, Yeniocak $\mathrm{S}$, Özdoğan Ü. Deplase olekranon kırıklı olgularda germe bandı tekniği sonuçlarımız. J Kartal TR 2007;XVIII(2):77-82.

17. Çetinus $E$, Hüner $H$, Cever İ. Olekranon kırıklarında cerrahi tedavi sonuçlarımız. Acta Orthop Traum Turc 1991;25:94-6.

18. Önçağ H, Özyalçın H, Aktuğlu K. Olekranon kırıklarının cerrahi tedavisi. Acta Orthop Traum Turc 1989;23:118-20.

19. Baecher N, Edwards S. Olecranon fractures. J Hand Surg Am 2013;38(3):593-604. CrossRef

20. Bailey CS, MacDermid J, Patterson SD, King GJ. Outcome of plate fixation of olecranon fractures. J Orthop Trauma 2001;15(8):542-8.

21. Erturer RE, Sever C, Sonmez MM, Ozcelik IB, Akman S, Ozturk I. Results of open reduction and plate osteosynthesis in comminuted fracture of olecranon. J Shoulder Elbow Surg 2011;20(3):449-54. CrossRef

22. Hume MC, Wiss DA. Olecranon fractures. A clinical and radiographic comparison of tension band wiring and plate fixation constructs. Clin Orthop Relat Res 1992;(285):229-35.

23. Wu CC, Tai CL, Shih CH. Biomechanical comparison for different configurations of tension band wiring techniques in treating an olecranon fracture. J Trauma 2000;48(6):1063-7.

24. Argintar E, Cohen M, Eglseder A, Edwards S. Clinical results of olecranon fractures treated with multiplanar locked intramedullary nailing. J Orthop Trauma 2013;27(3):140-4. CrossRef

25. Argintar E, Martin BD, Singer A, Hsieh AH, Edwards S. A biomechanical comparison of multidirectional nail and locking plate fixation in unstable olecranon fractures. J Shoulder Elbow Surg 2012;21(10):1398-405. CrossRef

26. Morrey BF. Current concepts in the treatment of fractures of radial head, the olecranon, and the coronoid. Instr Course Lect 1995;44:175-85.

27. Simpson NS, Goodman LA, Jupiter JB. Contoured LCDC plating of the proximal ulna. Injury 1996;27(6):411-7.

28. Rommens PM, Schneider RU, Reuter M. Functional results after operative treatment of olecranon fractures. Acta Chir Belg 2004:104(2):191-7.

29. Horne JG, Tanzer TL. Olecranon fractures: A review of 100 cases. J Trauma 1981;21(6):469-72.

30. Papagelopoulos PJ, Morrey BF. Treatment of nonunion of olecranon fractures. J Bone Joint Surg Br 1994;76(4):627-35. 